\title{
Numerical Analysis of the Performance of an Innovative Daylighting System Named Modified Double Light Pipe
}

\author{
P. Zazzini ${ }^{1 *}$, A. Di Crescenzo ${ }^{1}$, R. Giammichele ${ }^{2}$ \\ ${ }^{1}$ Dept. INGEO Univ.“G. D’Annunzio” Chieti-Pescara, Viale Pindaro 4, 65127 PESCARA, Italy \\ ${ }^{2}$ Engineer, Via A.Gramsci n ${ }^{\circ} 10 / \mathrm{A}$ - Vasto $(\mathrm{CH})$
}

Corresponding Author Email: zazzini@unich.it

https://doi.org/10.18280/ti-ijes.652-432

Received: 20 March 2021

Accepted: 13 May 2021

\section{Keywords:}

light pipe, double light pipe, modified double light pipe, daylight, undergroung buildings

\begin{abstract}
This paper focuses on the performance of an innovative daylighting system named Modified Double Light Pipe (MDLP). It consists of a device integrating a Double Light Pipe (DLP) with a light shelf. The DLP has been created by the authors to enter daylight into two levels underground buildings. It involves an excessive bulk and the risk of glare in the passage environment. The MDLP is an attempt to solve these problems by coupling the DLP and the light shelf technologies.

The authors used a numerical approach modeling the MDLP by the software Rhinoceros and simulating its performance by Grasshopper plugins Ladybug and Honeybee. After calibrating the software by the comparison between numerical and experimental data on the DLP, they carried out a numerical analysis on the MDLP in steady-state and dynamic conditions. In steady-state regime, the MDLP performs better than the DLP, giving quite a uniform illuminance distribution on the horizontal work plane. This is confirmed by the results of the dynamic analysis, carried out evaluating the metric Spatial Daylight Autonomy (sDA). Moreover, the risk of glare is avoided by the MDLP, thanks to the presence of the light shelf that prevents the observer from seeing the device directly.
\end{abstract}

\section{INTRODUCTION}

Human well-being inside homes is a very important issue in many areas of the world. Before the COVID-19 pandemic, the Italian population spent approximately $60 \%$ of their time at home. Due to the spread of the pandemic, several studies have estimated that adults spend about $87 \%$ up to $90 \%$ of their time inside buildings everywhere in the world. The COVID-19 pandemic forces us to reflect on the need of modifying the way to design residential buildings, work offices, or schools [1-4].

Smart working raises the need of adapting residential buildings to be used in a different way than that of a standard home. Architects and Engineers have to consider new aspects in the design process, adjusting residential environments to behaviours and activities not foreseen in the pre-pandemic planning. To guarantee the performance of new activities, while maintaining the safety, comfort, and psychophysical well-being of individuals, they have to evaluate the paths of common and private areas, the air changes necessary to ensure the healthiness of the environments, taking into account the increasing occupation time of domestic spaces.

Moreover, air pollution within residential environments in large cities is a topical issue in many academic studies. They focus on pollutants entering from the outdoor or produced by furniture or hygiene products [5].

In the case of people living in underground and/or basement environments [6], there are also problems relating to humidity control and the possible presence of Radon gas, which is harmful to human health [7].

Natural lighting, solar radiation, and ventilation are of great importance for sanitary purposes. Scientific literature has shown how solar radiation carries out an effective antibacterial action, together with thermal and luminous effects [8]. National standards in Italy request the presence of natural light in residential environments and working spaces to ensure visual comfort conditions, depending on the destination use of buildings. The absence of natural light can be very dangerous to human health, weakening the immune system, impairing the production of hormones, and altering the circadian and sleeping rhythms. It can generate altered mood and depression, but also osteoporosis and rickets [9].

Furthermore, incorrect exposure to indoor lighting can negatively affect attention, concentration, and functionality.

It is very important to evaluate the distribution of daylight inside the building. This is possible through numerical methods, using software able to determine the annual behaviour of light [10].

In underground areas of buildings, or large plan area environment, it is increasing the use of technological devices to make available or improve natural light presence. In this context, light pipes play an important role. The use of light pipes is more and more increasing, particularly in residential or commercial buildings [11-13].

Some authors use the experimental approach on scale model under real sky in determining the performance of light pipes or similar devices for daylight [14]. This is a simple and effective method although some factors often affect the results decreasing their accuracy; for example, the presence of direct solar radiation, or particular sky luminance distributions.

Numerical simulations can integrate data from experimental analysis and allow determining dynamic daylight parameters able to define the performance of daylighting devices. 
In this paper, the authors present the Modified Double Light Pipe (MDLP), which is an attempt of improving the performance of the Double Light Pipe (DLP), a device set up by the authors to distribute natural light in two levels of underground buildings [15-18]. The DLP consists of a traditional light pipe covered on its exterior surface with the same highly reflective film applied on its interior surface and coupled with a transparent concentric tube. In this way, natural light enters the final room by the internal tube and the passage area by the interspace between the two tubes.

An excessive bulk and a concentration of light near the device partially penalize the performance of the DLP, as well as the risk of glare in the passage environment due to the high luminance of the upper portion of the system. The MDLP has the goal to solve these problems by applying a reflecting surface on the ceiling and a circular light shelf around the transparent tube to diffuse light more uniformly on the work plane while widening the upper portion of the device preventing the risk of glare (see Figure 1).
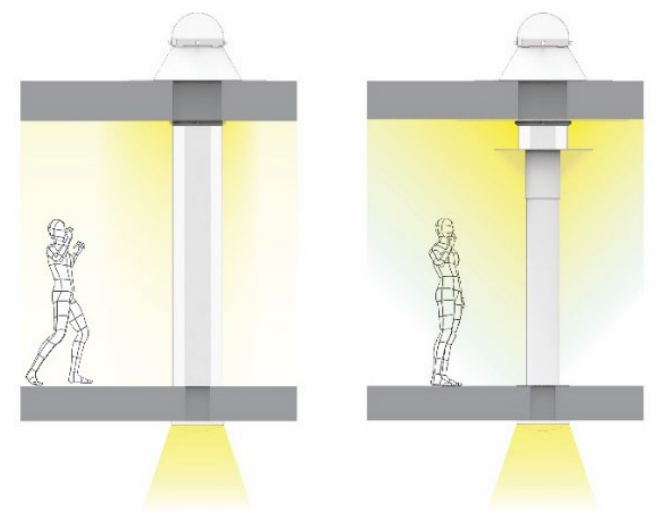

Figure 1. View of the DLP and the MDLP

\section{THE DLP AND MDLP SYSTEMS}

A light pipe distributing daylight in the second hypogeal floor of an underground construction mandatorily passes through an intermediate floor, producing a significant encumbrance in the middle of the room. The double light pipe (DLP), proposed by Baroncini et al. [15-17] and Boccia et al. [18], has been made to lighten this drawback, being able to illuminate both the underground levels: the passage area and the final room.

It consists of two concentric pipes: the internal one performs as a traditional light pipe and illuminates the final room, while the external transparent one introduces daylight in the passage room. Thanks to this double illuminating function, it can be located in the middle of the room, despite its encumbrance.

In the intermediate room, the DLP introduces good quality light. It is particularly suitable for large showrooms or museums, but glare phenomena are possible due to the high luminance of the upper portion of the device. In addition, it gives an uneven distribution of light, more concentrated near the tube.

Starting from these considerations, the authors have devised a system able to improve the performance of the DLP, named Modified Double Light Pipe (MDLP).

The MDLP is made revising the DLP: a reflecting shelf fixed to the ceiling and a circular light shelf, $300 \mathrm{~mm}$ distant from the ceiling, have been added. The last can reflect light toward the ceiling and improve the uniformity of light distribution on the work plane. In addition, this prevents the occupants from seeing the upper portion of the system avoiding the risk of glare. Finally, the lower part of the external tube is cut and the overall dimensions of the system are significantly reduced. Figure 1 shows a view of the room equipped with the DLP and the MDLP, while Figure 2 shows the principal components of the system.

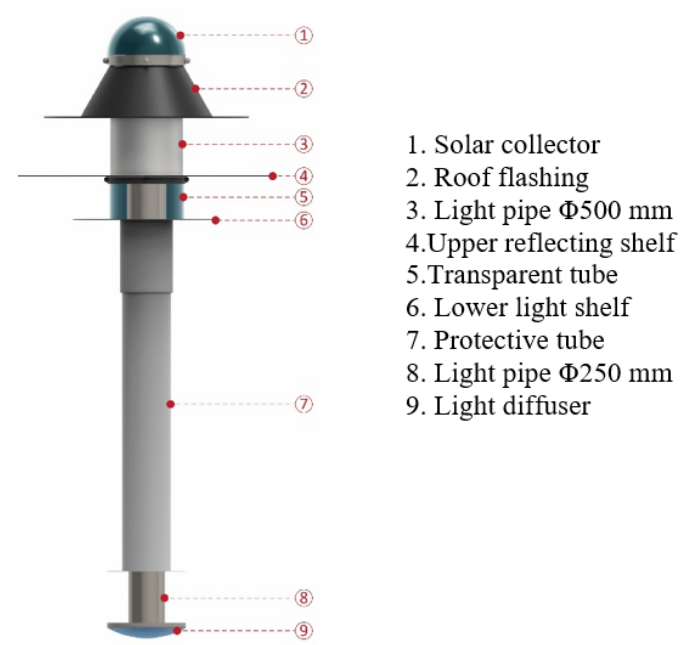

Figure 2. Principal components of the system

\section{METHODOLOGY OF ANALYSIS}

The authors used a numerical method to analyse the performance of the MDLP. Firstly, they drew a threedimensional model of the device using the 3D modeling software Rhinoceros and then they carried out steady-state and dynamic simulations to determine its performance by Grasshopper plugins Ladybug and Honeybee.

The simulation activity has been preceded by the software calibration, carried out through the comparison of numerical data with experimental results on a 1:2 scale model of the DLP.

\subsection{Software of analysis}

The mathematical model of a Light Pipe, Double Light Pipe, or Modified Double Light Pipe is more complex than that of a window; therefore, the use of commercial software is excluded. The major difficulty consists in simulating the light path inside the pipe, due to the high number of reflections from its internal surface.

In this paper, the authors used a series of calculation engines (software, tools, and plug-ins) managed through combination scripts, relying on the "basic" program Rhinoceros, a 3D modeling software based on NURBS curves and surfaces.

Unlike traditional software, Rhinoceros uses an internal logic/mathematical programming language called Grasshopper that uses a visual language (VPL) which allows creating complex algorithms through the combination of precompiled blocks; it boasts a very wide range of plug-ins that expands its sectors of use. In this work, the authors used the plug-ins Honeybee and Ladybug.

Honeybee, a master plug-in in the lighting industry, allows integrating into Grasshopper some extensions as Daysim, OpenStudio, EnergyPlus and Radiance, while Ladybug is a data management software that processes the results from 
Honeybee according to the programmer's needs.

The software allows performing steady-state and dynamic analyses. In the first case, it is possible to define the desired time and sky conditions, while, in the second, the program determines the most likely sky conditions for the selected site in the time interval defined. The statistically most probable sky conditions are identified and managed by the .epw file downloadable from the EnergyPlus website.

\subsection{Daylighting parameters}

The Standard IES LM-83-12 [19] proposed the metric Spatial Daylight Autonomy (sDA300/50\%) to determine natural light distribution in interior areas in dynamic conditions. The U.S. Green Building Council introduced sDA in LEED v4 [20] for the calculation of daylight credits in the Rating system of buildings.

The sDA is defined as "the percentage of floor area of the building that receives at least $300 \mathrm{~lx}$ for at least $50 \%$ of the annual occupied hours". It describes the portion of the floor area that receives enough daylight during the year. To get a good daylight distribution, maximizing sDA is needed.

\section{CALIBRATION ACTIVITY}

The authors carried out an experimental activity on a 1:2 scale model of the DLP and compared the results with numerical data from Ladybug and Honeybee.

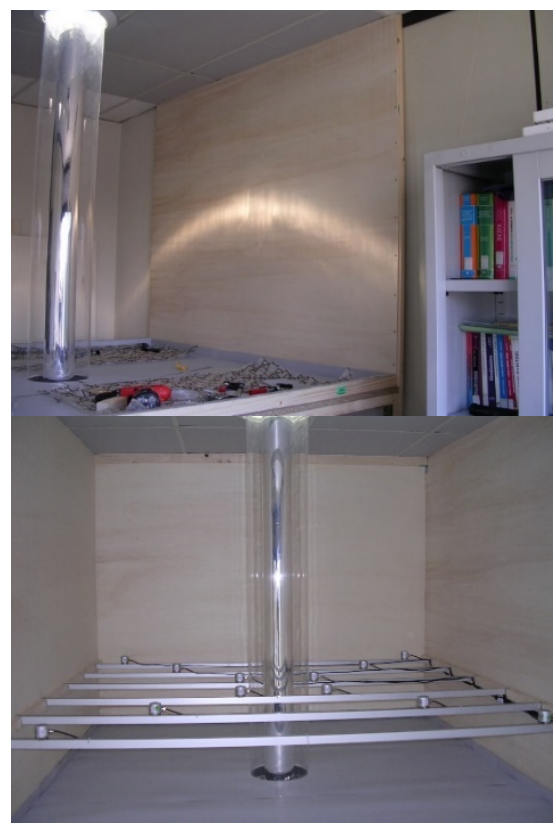

Figure 3. The DLP during the experimental activity

The experimental apparatus was built using a wooden 1:2 scale model $(1.9 \times 1.9 \mathrm{~m}, \mathrm{~h}=1.5 \mathrm{~m})$ which simulates a hypogeal room $(3.8 \times 3.8 \mathrm{~m}, \mathrm{~h}=3 \mathrm{~m})$. In the scale model, the work plane is $400 \mathrm{~mm}$ high on the floor $(\mathrm{h}=800 \mathrm{~mm}$ in real scale $)$. The vertical walls have been made with unpainted plywood and the floor and ceiling are covered with grey painted drawing paper. Figure 3 shows the model during the tests.

The experimental activity took place during two days: April the 1 st and the 2 nd, collecting data every hour (from 12 to 15 ) from 12 sensors arranged as shown in Figure 4.
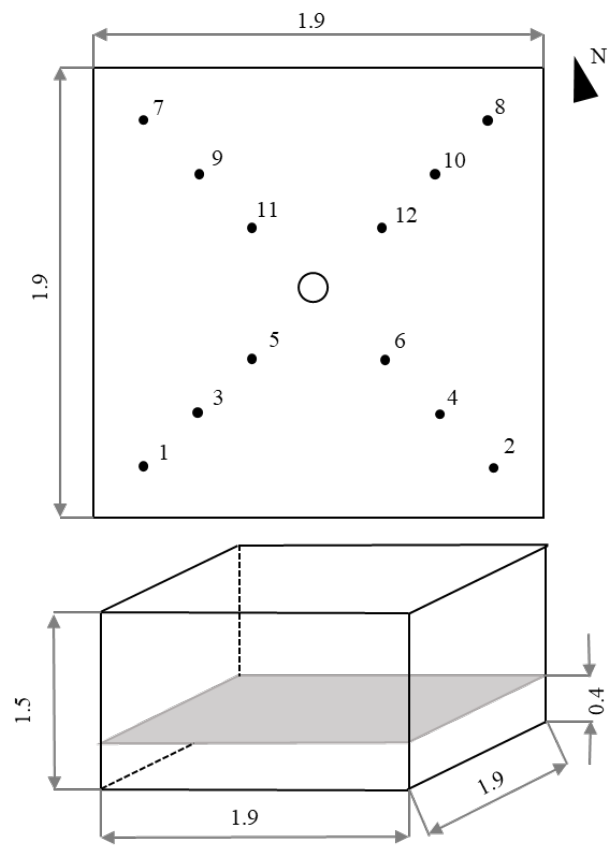

Figure 4. Room size of the experimental model

The reflection factors have been measured using a MINOLTA cm-508 D spectrophotometer. Data are shown in Table 1.

Table 1. Reflection factors of the 1:2 model of the DLP

\begin{tabular}{cc}
\hline Component & $\boldsymbol{\rho ( \% )}$ \\
\hline Ceiling & 67,5 \\
\hline Walls & 48,9 \\
\hline Floor & 67,5 \\
\hline
\end{tabular}

Figure 5 shows the results on April the $1^{\text {st }}$, while Figure 6 on April the $2^{\text {nd }}$, while Table 2 shows the percentage errors between numerical and experimental results of the calibration activity.

There is on average a good agreement between data. The percentage error is less than $10 \%$ in most cases. Some exceptions take place particularly on April the $2^{\text {nd }}$ at 14.00 , probably due to intense reflections from the tube. The maximum values are registered in positions 2 (37.2\%), 6 $(18.9 \%)$ and $1(16.2 \%)$. Once more, it is evidenced that reflections from the tube can give anomalies in the DLP performance.

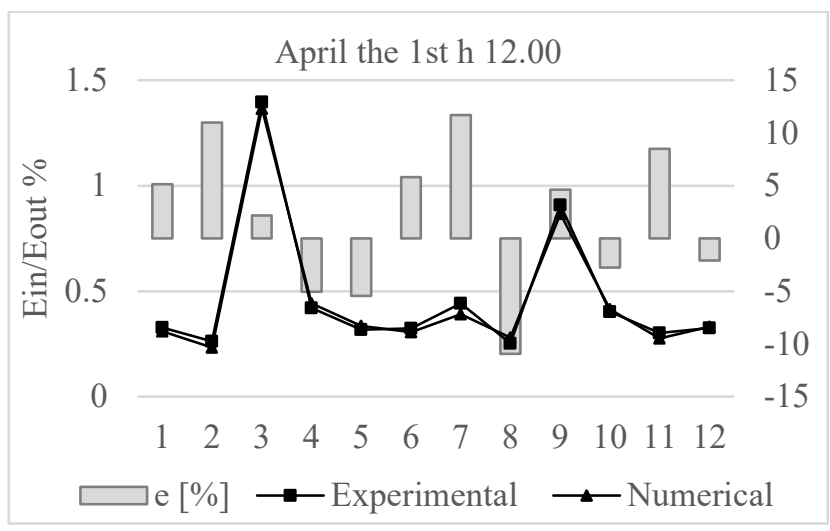

Figure 5. a. Calibration activity on April the $1^{\text {st }} \mathrm{h}=12.00$ 


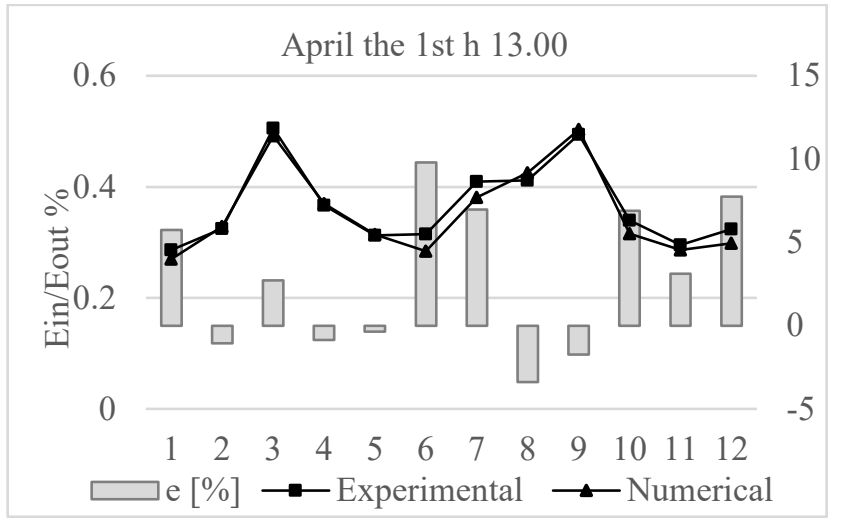

Figure 5. b. Calibration activity on April the $1^{\text {st }} \mathrm{h}=13.00$

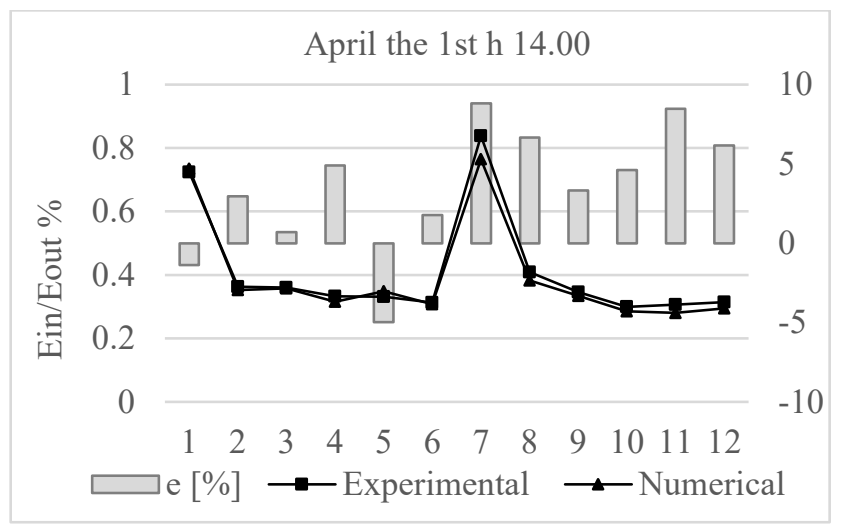

Figure 5. c. Calibration activity on April the $1^{\text {st }} \mathrm{h}=14.00$

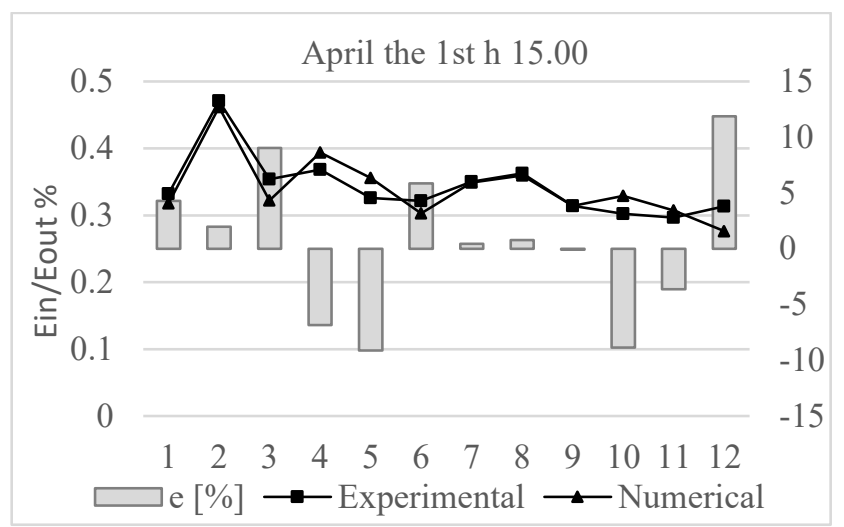

Figure 5. d. Calibration activity on April the $1^{\text {st }} \mathrm{h}=15.00$

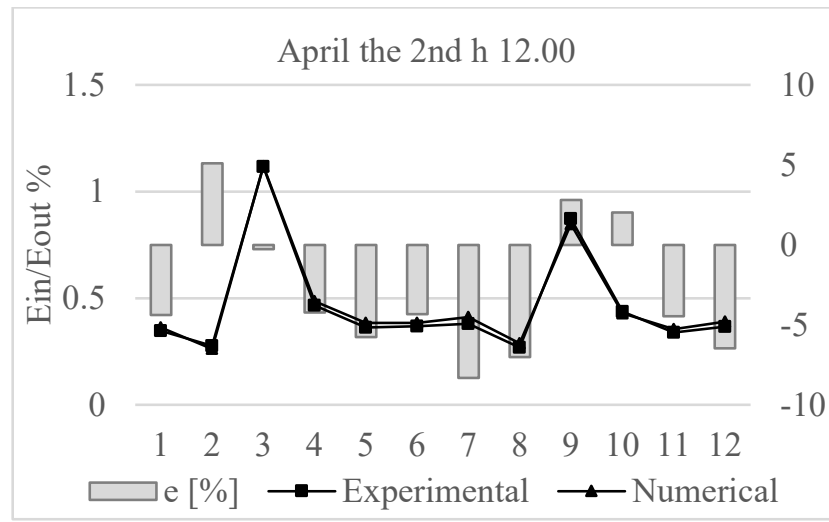

Figure 6. a. Calibration activity on April the $2^{\text {nd }} \mathrm{h}=12.00$

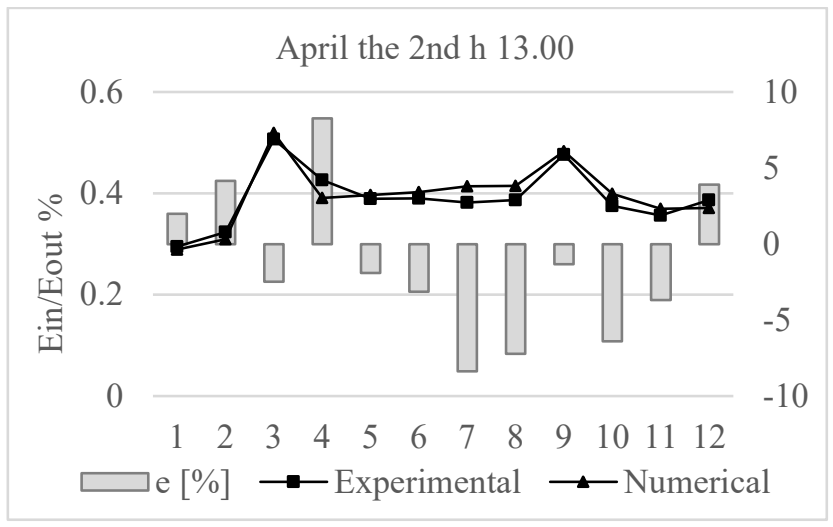

Figure 6. b. Calibration activity on April the $2^{\text {nd }} h=13.00$

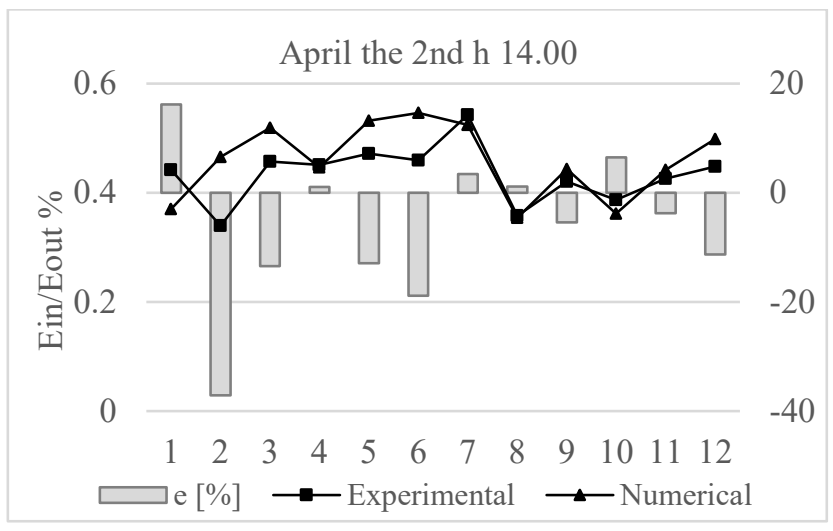

Figure 6. c. Calibration activity on April the $2^{\text {nd }} h=14.00$

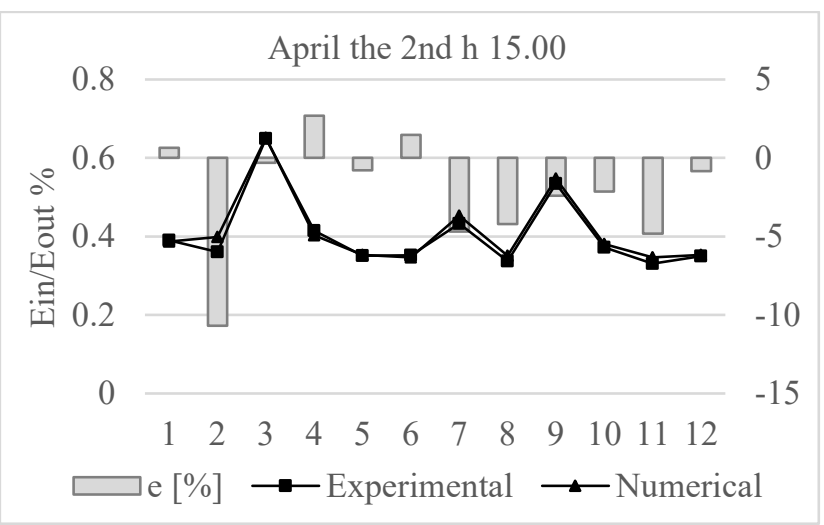

Figure 6. d. Calibration activity on April the $2^{\text {nd }} \mathrm{h}=15.00$

Table 2. Percentage error between numerical and experimental data registered during the calibration activity

\begin{tabular}{ccccccccc}
\hline \multicolumn{3}{c}{ April the 1 $^{\text {st }}$} & \multicolumn{5}{c}{ April the 2 $^{\text {nd }}$} \\
\hline $\mathbf{1}$ & 5.1 & 5.7 & -1.4 & 4.3 & -4.4 & 2.0 & 16.2 & 0.6 \\
$\mathbf{2}$ & 11.0 & -1.1 & 3.0 & 2.0 & 5.1 & 4.1 & -37.1 & -10.7 \\
$\mathbf{3}$ & 2.2 & 2.7 & 0.7 & 9.0 & -0.3 & -2.5 & -13.4 & -0.3 \\
$\mathbf{4}$ & -5.1 & -0.9 & 4.9 & -6.9 & -4.2 & 8.3 & 1.1 & 2.7 \\
$\mathbf{5}$ & -5.4 & -0.4 & -5.0 & -9.1 & -5.8 & -1.9 & -12.9 & -0.8 \\
$\mathbf{6}$ & 5.8 & 9.8 & 1.8 & 5.8 & -4.3 & -3.1 & -18.9 & 1.5 \\
$\mathbf{7}$ & 11.7 & 7.0 & 8.8 & 0.5 & -8.3 & -8.4 & 3.4 & -4.7 \\
$\mathbf{8}$ & -10.9 & -2.4 & 6.7 & 0.8 & -7.0 & -7.2 & 1.1 & -4.2 \\
$\mathbf{9}$ & 4.6 & -1.7 & 3.3 & -0.1 & 2.8 & -1.3 & -5.5 & -2.4 \\
$\mathbf{1 0}$ & -2.7 & 6.9 & 4.6 & -8.9 & 2.0 & -6.4 & 6.5 & -2.1 \\
$\mathbf{1 1}$ & 8.5 & 3.1 & 8.5 & -3.6 & -4.5 & -3.7 & -3.7 & -4.8 \\
$\mathbf{1 2}$ & -2.1 & 7.7 & 6.2 & 11.9 & -6.5 & 3.9 & -11.3 & -0.8 \\
& $\mathbf{1 2}$ & $\mathbf{1 3}$ & $\mathbf{1 4}$ & $\mathbf{1 5}$ & $\mathbf{1 2}$ & $\mathbf{1 3}$ & $\mathbf{1 4}$ & $\mathbf{1 5}$ \\
\hline
\end{tabular}




\section{NUMERICAL ANALYSIS}

Simulations of the performance of the DLP and the MDLP have been carried out in a $5 \times 5 \mathrm{~m}$ square room, $\mathrm{h}=3 \mathrm{~m}$, with a horizontal work plane $800 \mathrm{~mm}$ high on the floor (see Figure 7), using climatic conditions of Pescara (Italy).
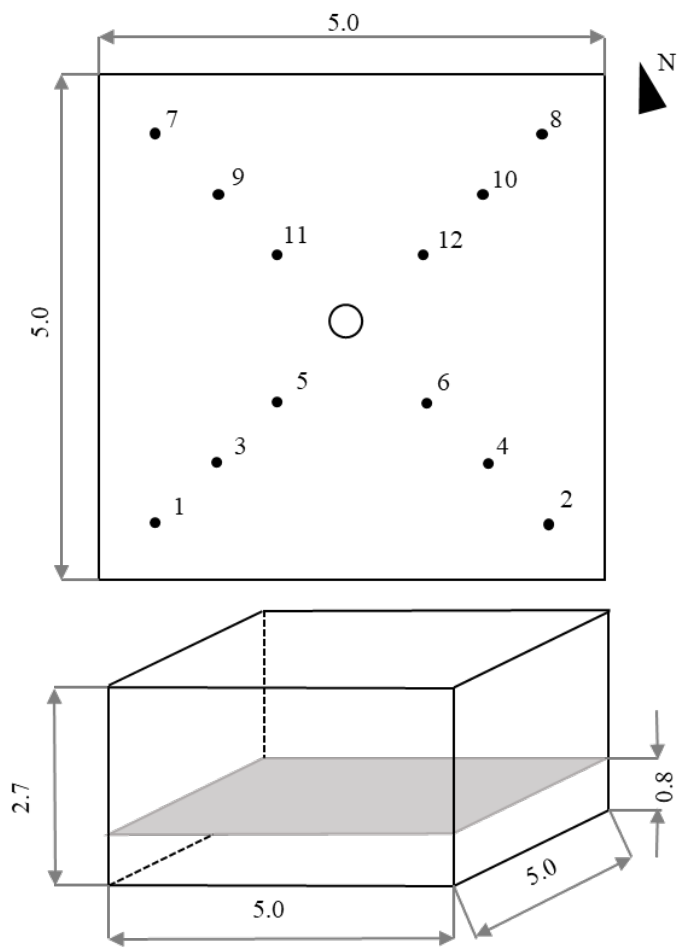

Figure 7. Room size of simulated models

\subsection{Steady-state analysis}

The steady-state analysis has been carried out for both models on June the $21^{\text {st }}$ under CIE Sunny sky conditions. This is the most representative situation in the year to compare the performance of DLP and MDLP. The illuminance values calculated in three representative hours of the day $(10.00$, 13.00, and 16.00) are shown in Figures 8, 9, and 10.

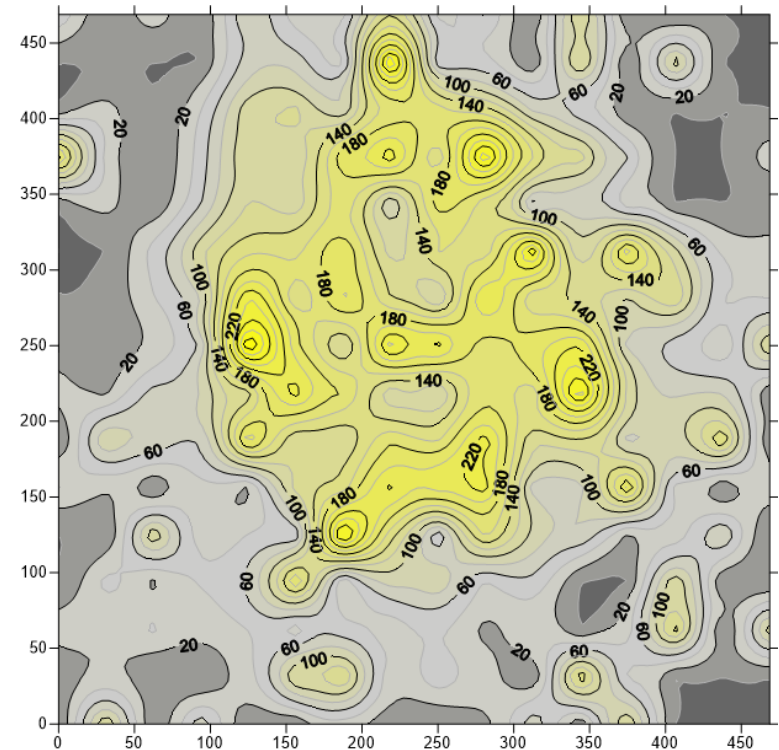

Figure 8. a. Illuminance on the work plane (DLP $-\mathrm{h} 10.00)$

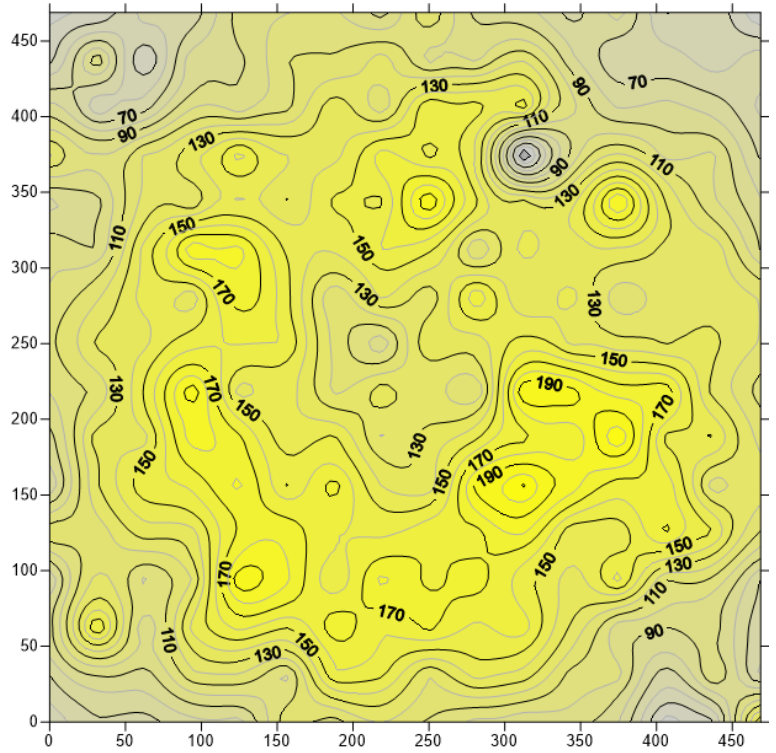

Figure 8. b. Illuminance on the work plane (MDLP $-\mathrm{h}$

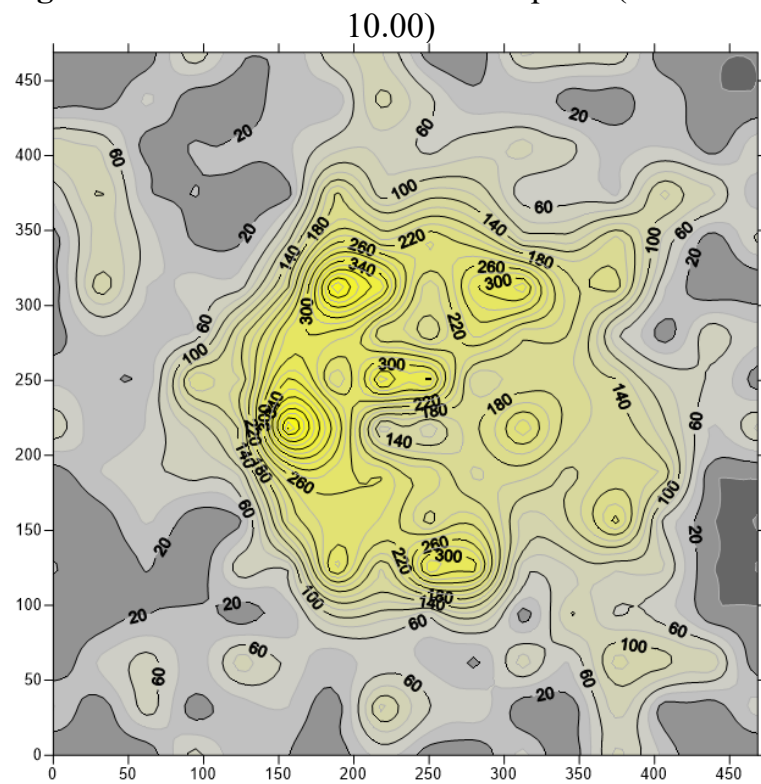

Figure 9. a. Illuminance on the work plane (DLP - 13.00)

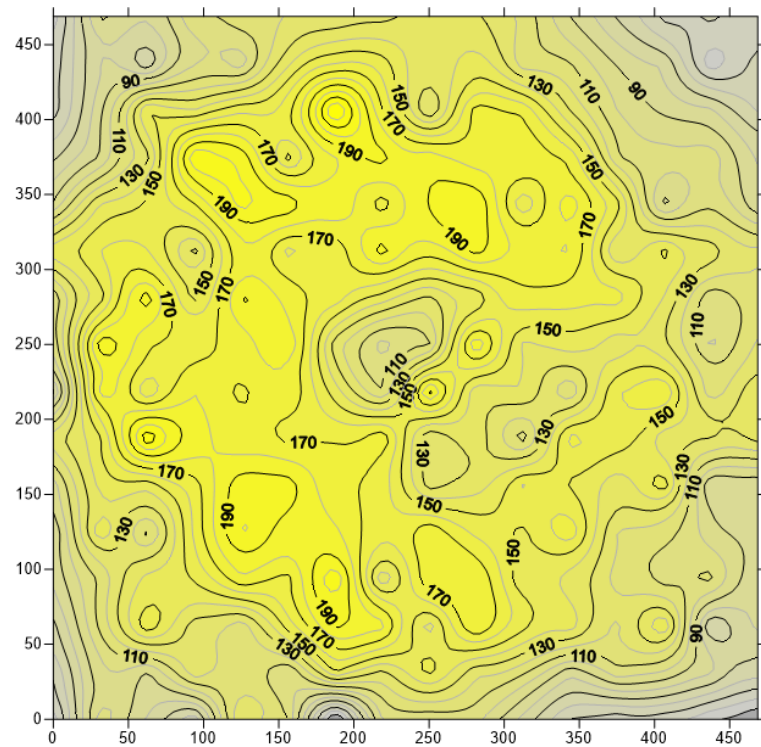

Figure 9. b. Illuminance on the work plane (MDLP - h $13.00)$ 


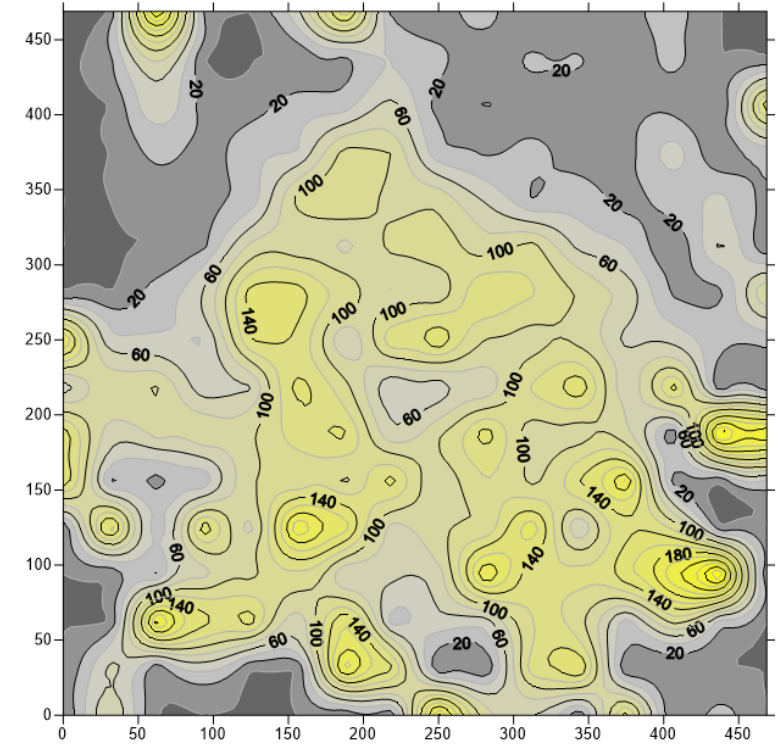

Figure 10. a. Illuminance on the work plane (DLP - h 16.00)

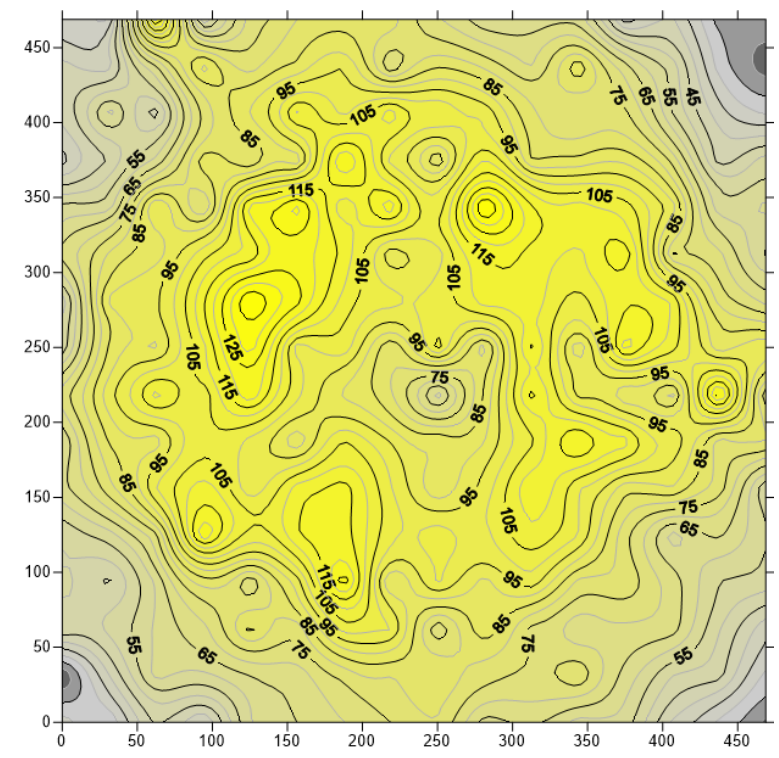

Figure 10. b. Illuminance on the work plane (MDLP - 16.00)

The results show that the DLP gives a symmetrical distribution of light around the system with an illuminance concentration in the middle of the room and some localized symmetrical peaks. Peak values of about $220 \mathrm{~lx}$ take place at 10.00, $300 \mathrm{~lx}$ at 13.00 and $140 \mathrm{~lx}$ at 16.00 (see Figures 8.a, 9.a and 10.a).

The illuminance distribution is quite symmetrical around the tube all over on the work pane at every time, but it rapidly decreases up to $20 \mathrm{~lx}$ going away from the device.

On the contrary, the modified system (MDLP) produces more uniform illuminance values and the presence of the reflective shelf allows obtaining on average an increasing lighting level all over the room.

Moreover, the MDLP allows avoiding the risk of glare thanks to the shielding offered by the lower shelf. It is possible to confirm that the improving modification applied to the system increases its lighting performance.

\subsection{Dynamic analysis}

To determine the annual performance of the system, the authors have carried out a numerical analysis in dynamic conditions, also taking into account the night hours, which represent non-functioning conditions for the system.

The purpose of the analysis was to evaluate only the contribution of natural light without any support that would greatly increase the performance of the system. For this reason, in the simulation model, there is not any dimmer able to activate artificial lighting during the night.

Figure 11 and Figure 12 show sDA values respectively with the DLP and the MDLP.

\section{DLP}

SDA300/50: Spatial Daylight Authonomy (3001x/50\% h)

\begin{tabular}{|c|c|c|c|c|c|c|c|c|c|c|c|c|c|c|c|}
\hline 0 & 0 & 16 & 0 & 0 & 0 & 18 & 29 & 35 & 18 & 0 & 0 & 0 & 16 & 0 & 0 \\
\hline 0 & 0 & 0 & 9 & 3 & 34 & 12 & 2 & 18 & 31 & 7 & 21 & 27 & 7 & 22 & 0 \\
\hline 3 & 0 & 20 & 0 & 0 & 9 & 0 & 3 & 13 & 3 & 14 & 9 & 8 & 20 & 0 & 0 \\
\hline 0 & 26 & 0 & 26 & 29 & 19 & 18 & 31 & 18 & 20 & 5 & 0 & 9 & 0 & 31 & 0 \\
\hline 0 & 0 & 28 & 8 & 10 & 8 & 37 & 42 & 39 & 31 & 31 & 17 & 25 & 1 & 17 & 23 \\
\hline 0 & 0 & 16 & 15 & 30 & 41 & 39 & 40 & 38 & 40 & 34 & 37 & 11 & 10 & 29 & 20 \\
\hline 0 & 34 & 34 & 12 & 37 & 40 & 33 & 22 & 26 & 37 & 40 & 40 & 22 & 11 & 28 & 0 \\
\hline 0 & 0 & 11 & 29 & 33 & 33 & 18 & 30 & 28 & 24 & 39 & 37 & 33 & 13 & 24 & 19 \\
\hline 12 & 19 & 29 & 25 & 36 & 36 & 14 & 28 & 27 & 17 & 40 & 43 & 27 & 16 & 3 & 29 \\
\hline 0 & 10 & 34 & 17 & 25 & 40 & 37 & 20 & 21 & 38 & 38 & 38 & 30 & 0 & 0 & 1 \\
\hline 0 & 14 & 12 & 9 & 26 & 20 & 40 & 39 & 20 & 40 & 36 & 35 & 18 & 28 & 0 & 6 \\
\hline 0 & 21 & 27 & 11 & 17 & 35 & 41 & 41 & 39 & 37 & 34 & 19 & 23 & 15 & 28 & 0 \\
\hline 0 & 0 & 32 & 0 & 24 & 20 & 16 & 15 & 24 & 20 & 33 & 32 & 0 & 23 & 24 & 5 \\
\hline 0 & 0 & 3 & 12 & 26 & 36 & 15 & 22 & 37 & 13 & 32 & 36 & 0 & 12 & 0 & 0 \\
\hline 0 & 0 & 0 & 0 & 0 & 38 & 0 & 41 & 31 & 27 & 36 & 18 & 20 & 0 & 0 & 0 \\
\hline 0 & 0 & 0 & 0 & 0 & 13 & 0 & 31 & 7 & 18 & 12 & 0 & 0 & 8 & 0 & 0 \\
\hline \hline
\end{tabular}

Number of grid points: 256

Annual hours: 8760

$50 \%$ of the annual hours: 4380

Number of points with values $\geq 50 \%$ : 0

sDA300/50: $0 \%$

\section{Figure 11. sDA 300/50 with DLP}

The DLP system produces an sDA300/50 equal to $0 \%$, but values of about $25-40 \%$ take place in a circular area around the tube, decreasing towards the edges of the room.

The results of the analysis show that the DLP would perform well when installed in environments with a target between 150 and $250 \mathrm{~lx}$, particularly near the center of the room.

In the case of the MDLP installed in the room, the sDA3001x/50 is close to $10 \%$.

Considering a period of $40 \%$ of the year instead of $50 \%$, the value of sDA would be between $20 \%$ and $25 \%$, which is certainly more representative of the distribution obtained.

The MDLP has uniform illuminance values on the edges of the room, but decreasing toward the center.

Thanks to the shielding action offered by the shelf interposed between the light source and the observer, it is possible to think that this system allows satisfactory levels of illuminance within the room.

It is verified that the DLP gives light peaks of illuminance in the central area of the room while the MDLP produces higher values on the edges of the room, but they tend to zero in the center. This trend is probably caused by the presence of 
the upper and lower shelves of the system.

In short, sDA values show that the MDLP allows obtaining higher values and a more uniform distribution of light on the work plane, compared to the DLP.

Moreover, if the analysis of the SDA parameter would be reduced to a reference target equal to $250 \mathrm{~lx}$, more representative results of the analyzed models would be obtained.

\section{MDLP}

SDA300/50: Spatial Daylight Authonomy (3001x/50\% h)

\begin{tabular}{|l|c|c|c|c|c|c|c|c|c|c|c|c|c|c|c|}
\hline 47 & 49 & 51 & 48 & 49 & 15 & 47 & 44 & 46 & 47 & 49 & 48 & 50 & 50 & 50 & 47 \\
\hline 50 & 51 & 50 & 47 & 47 & 11 & 33 & 10 & 7 & 19 & 45 & 40 & 47 & 49 & 49 & 52 \\
\hline 52 & 41 & 46 & 35 & 10 & 6 & 6 & 6 & 3 & 7 & 3 & 38 & 39 & 48 & 50 & 51 \\
\hline 49 & 45 & 19 & 14 & 30 & 11 & 8 & 3 & 3 & 10 & 10 & 14 & 12 & 35 & 46 & 49 \\
\hline 49 & 48 & 19 & 7 & 7 & 10 & 2 & 0 & 0 & 0 & 2 & 14 & 9 & 15 & 4 & 49 \\
\hline 48 & 17 & 13 & 8 & 7 & 8 & 0 & 0 & 0 & 0 & 1 & 11 & 11 & 8 & 42 & 47 \\
\hline 49 & 4 & 9 & 8 & 5 & 0 & 0 & 0 & 0 & 0 & 0 & 13 & 11 & 6 & 36 & 47 \\
\hline 48 & 19 & 12 & 2 & 3 & 0 & 0 & 0 & 0 & 0 & 0 & 3 & 10 & 9 & 25 & 49 \\
\hline 46 & 3 & 7 & 8 & 3 & 0 & 0 & 0 & 0 & 0 & 0 & 7 & 10 & 9 & 39 & 47 \\
\hline 49 & 30 & 11 & 8 & 2 & 5 & 0 & 0 & 0 & 0 & 0 & 5 & 8 & 8 & 16 & 50 \\
\hline 48 & 39 & 9 & 6 & 3 & 6 & 0 & 0 & 0 & 0 & 4 & 12 & 8 & 3 & 46 & 49 \\
\hline 49 & 43 & 18 & 10 & 9 & 10 & 7 & 0 & 9 & 0 & 9 & 4 & 6 & 15 & 50 & 47 \\
\hline 49 & 27 & 47 & 22 & 5 & 7 & 8 & 1 & 10 & 0 & 8 & 2 & 13 & 47 & 45 & 42 \\
\hline 51 & 49 & 49 & 45 & 25 & 12 & 7 & 6 & 14 & 3 & 8 & 15 & 24 & 48 & 51 & 52 \\
\hline 53 & 53 & 49 & 47 & 46 & 44 & 34 & 46 & 26 & 35 & 38 & 47 & 47 & 51 & 51 & 49 \\
\hline 47 & 50 & 51 & 50 & 49 & 45 & 40 & 45 & 47 & 47 & 47 & 49 & 49 & 51 & 50 & 49 \\
\hline
\end{tabular}

Number of grid points: 256

Annual hours: 8760

$50 \%$ of the annual hours: 4380

Number of points with values $\geq 50 \%: 25$

sDA300/50:9.77\%

Figure 12. sDA 300/50 with DLP

\section{CONCLUSIONS}

In this paper, the authors have proposed an innovative daylighting device called Modified Double Light Pipe, made by modifying the Double Light Pipe with a light shelf applied on the system.

Through a numerical analysis in steady-state and dynamic conditions, they have compared the performance of the MDLP and the DLP applied in an underground environment.

The results show how the MDLP gives a more uniform distribution of light on the work plane. Peak values of illuminance that take place around the DLP are eliminated and the risk of glare is avoided.

The sDA metric, calculated in dynamic conditions, is increased from $0 \%$ to $9.77 \%$. Therefore, a significant improvement in visual comfort and a good contribution to energy saving is expected. Besides, the encumbrance of the system is significantly reduced.

Further developments of the research will focus on deepening the analysis of the performance of the system through experimental investigations. Finally, the author intends to study in-depth the technological components of the device, and its applicability in hypogeal buildings.

\section{REFERENCES}

[1] D'alessandro, D., Gola, M., Appolloni, L., Dettori, M., Fara, G.M., Rebecchi, A., Capolongo, S. (2020). COVID-19 and living space challenge. Well-being and public health recommendations for a healthy, safe, and sustainable housing. Acta Bio Medica: Atenei Parmensis, 91(9-S): 61. https://doi.org/10.23750/abm.v9li9-S.10115

[2] Shaikh, P.H., Nor, N.M., Nallagownden, P., Elamvazuthi, I., Ibrahim, T. (2013). Robust stochastic control model for energy and comfort management of buildings. Australian Journal of Basic and Applied Sciences, 7(10): 137-144.

[3] Capolongo, S., Rebecchi, A., Buffoli, M., Appolloni, L., Signorelli, C., Fara, G.M., D’Alessandro, D. (2020). COVID-19 and cities: From urban health strategies to the pandemic challenge. A decalogue of public health opportunities. Acta Bio Medica: Atenei Parmensis, 91(2): 13. https://doi.org/10.23750/abm.v91i2.9515

[4] Xu, J. (2020). The Impact of Epidemics on Future Residential Buildings in China. Rochester Institute of Technology. Rochester, USA, 2019.

[5] Klepeis, N.E., Nelson, W.C., Ott, W.R., Robinson, J.P., Tsang, A.M., Switzer, P., Engelmann, W.H. (2001). The National Human Activity Pattern Survey (NHAPS): A resource for assessing exposure to environmental pollutants. Journal of Exposure Science \& Environmental Epidemiology, 11(3): 231-252. https://doi.org/10.1038/sj.jea.7500165

[6] Mezzoiuso, A.G., Gola, M., Rebecchi, A., Riccò, M., Capolongo, S., Bufoli, M., Signorelli, C. (2017). Ambienti confinati e salute: Revisione sistematica della letteratura sui rischi legati all'utilizzo dei seminterrati a scopo abitativo. Acta Bio Medica: Atenei Parmensis, 88(3): 375. https://doi.org/10.23750/abm.v\%vi\%i.6741

[7] Pasculli, A., Rizzo, F., Zazzini, P. (2019). Probabilistic estimate of indoor radon distribution in Abruzzo (central Italy): comparison of different statistical methods. In Journal of Physics: Conference Series, 1391(1): 012001. https://doi.org/10.1088/1742-6596/1391/1/012001

[8] Fahimipour, A.K., Hartmann, E.M., Siemens, A., Kline, J., Levin, D.A., Wilson, H., Van Den Wymelenberg, K. (2018). Daylight exposure modulates bacterial communities associated with household dust. Microbiome, 6(1): 1-13. https://doi.org/10.1186/s40168018-0559-4

[9] De Giorgi, A., Menegatti, A.M., Fabbian, F., Portaluppi, F., Manfredini, R. (2013). Circadian rhythms and medical diseases: Does it matter when drugs are taken? European Journal of Internal Medicine, 24(8): 698-706. https://doi.org/10.1016/j.ejim.2013.03.019

[10] Konis, K. (2017). A novel circadian daylight metric for building design and evaluation. Building and Environment, 113: 22-38. https://doi.org/10.1016/j.buildenv.2016.11.025

[11] Canziani, R., Peron, F., Rossi, G. (2004). Daylight and energy performances of a new type of light pipe. Energy and Buildings, 36(11): 1163-1176. https://doi.org/10.1016/j.enbuild.2004.05.001

[12] Jenkins, D., Muneer, T., Kubie, J. (2005). A design tool for predicting the performances of light pipes. Energy and Buildings, 37(5): 485-492. https://doi.org/10.1016/j.enbuild.2004.09.014 
[13] Zazzini, P., Chella, F., Scarduzio, A. (2006). Numerical and experimental analysis of light pipes' performances: comparison of the obtained results. In Proceedings of PLEA, 1: 219-224.

[14] Boccia, O., Zazzini, P. (2015). Daylight in buildings equipped with traditional or innovative sources: A critical analysis on the use of the scale model approach. Energy and Buildings, 86: 376-393. https://doi.org/10.1016/j.enbuild.2014.10.003

[15] Baroncini, C., Boccia, O., Chella, F., Zazzini, P. (2010). Experimental analysis on a 1: 2 scale model of the double light pipe, an innovative technological device for daylight transmission. Solar Energy, 84(2): 296-307. https://doi.org/10.1016/j.solener.2009.11.011

[16] Baroncini, C., Chella, F., Zazzini, P. (2008). Numerical and experimental analysis of the 'Double Light Pipe', a new system for daylight distribution in interior spaces. International Journal of Low-Carbon Technologies, 3(2): 110-125. https://doi.org/10.1093/ijlct/3.2.110

[17] Boccia, O., Chella, F., Zazzini, P. (2011). Numerical analysis on daylight transmission and thermal comfort in the environments containing devices called "Double Light Pipes". In World Renewable Energy CongressSweden; 8-13 May; 2011; Linköping; Sweden, 057:
1914-1921. Linköping University Electronic Press. https://doi.org/10.3384/ecp110571914

[18] Boccia, O., Chella, F., Zazzini, P. (2012). Innovative devices for daylighting and natural ventilation in architecture. In Solar Radiation, 269-290. In Tech Rijeka, Croatia. https://doi.org/10.5772/34823

[19] Approved Method: IES Spatial Daylight Autonomy (sDA) and Annual Sunlight Exposure (ASE) standard by Illuminating Engineering Society, IES LM-83, 2012.

[20] LEED v4 for Building Design and Construction by Green Building Council, 2016

\section{NOMENCLATURE}

$\begin{array}{ll}\text { sDA300/50 } & \text { spatial daylight autonomy \% } \\ \mathrm{E}_{\text {in }} & \text { internal illuminance lx } \\ \mathrm{E}_{\text {out }} & \text { external illuminance lx } \\ \mathrm{e} & \text { error } \%\end{array}$

\section{Greek symbols}

$\rho$ visible reflection factor $\%$ 